\title{
A FERRAMENTA WIKI - DESAFIOS E CONTRIBUIÇÕES NA FORMAÇÃO UNIVERSITÁRIA PRESENCIAL
}

\author{
Andriza Machado Becker/Universidade Federal de Santa Maria
}

\begin{abstract}
RESUMO: A incorporação crescente das TICs ao processo de ensino-aprendizagem traz novas possibilidades na educação e desafia as práticas pedagógicas. Este trabalho tem por objetivo apresentar os resultados de uma experiência envolvendo o uso da ferramenta wiki em um curso de licenciatura presencial. Considera-se que essa ferramenta contribuiu colaborativamente para a discussão acerca da formação de professores na contemporaneidade, bem como para a familiarização e uso de recursos tecnológicos no ensino.
\end{abstract}

PALAVRAS-CHAVE: Ferramenta wiki; Formação de professores; Ensino-aprendizagem mediado por TICs.

ABSTRACT: The growing incorporation of ICT to teaching and learning process brings new possibilities in education and challenges of teaching practices. This paper aims to present the results of an experiment involving the use of the wiki tool in a degree face-to-face course. It is considered that this tool collaboratively contributed to the discussion around the teacher training in contemporary as well as for familiarization and use of technological resources in teaching.

KEYWORDS: Wiki tool; Teacher training; Teaching and learning mediated by ICTs.

\section{INTRODUÇÃO}

As tecnologias da informação e da comunicação (TICs) têm proporcionado a inserção de diversas ferramentas como apoio às práticas pedagógicas no cenário atual da educação. A utilização de ambientes virtuais de ensino-aprendizagem (AVEAs) é uma realidade já consolidada na modalidade de ensino a distância (EAD) e que também vem ganhando espaço no ensino presencial como forma de disponibilizar materiais online, tarefas e outros recursos auxiliares nas práticas de ensino-aprendizagem de forma colaborativa.

Essa realidade implica mudanças na formação profissional uma vez que, nesses ambientes, alteram-se as relações espácio-temporais e as formas de comunicação entre alunos e professores, assim como as dinâmicas de interação nos AVEAs permitem aos alunos assumirem o controle de sua forma de aprender.

Num AVEA é possível a inserção de várias mídias e recursos - o que torna a ferramenta um repositório de informações acessíveis de forma síncrona ou assíncrona. Já a mediação da comunicação entre os participantes do ambiente ocorre por meio do professor pesquisador - o qual é responsável pela elaboração e inserção do material didático de uma disciplina; e também do professor-tutor - figura que acompanha mais diretamente a realização das atividades e assessora pedagogicamente os alunos. Dessa forma: "quanto mais rica for essa mediação, mais chances de êxito teremos nesse processo” (DIAS, 2009, p. 28).

Dentre as diversas possibilidades e funcionalidades dos AVEAs, destaca-se a ferramenta wiki - recurso que permite a produção textual coletiva a partir de uma interface semelhante aos editores de textos. "Por sua natureza livre, mas destacadamente quando abertas a contribuições de 
um grande número de pessoas, as wikis giram em torno do seu conteúdo e não dos seus autores” (ABDO, 2009, p. 57). Essa é uma característica diferencial em relação a outras ferramentas como, por exemplo, o blog - no qual os conteúdos inseridos representam a construção individual de cada usuário.

Assim, o presente artigo tem por objetivo compartilhar uma experiência de ensinoaprendizagem envolvendo o uso da ferramenta wiki no AVEA Moodle ${ }^{i}$, enquanto suporte de apoio às atividades de uma disciplina do Curso de Pedagogia, modalidade presencial.

Para tanto, as seções organizam-se da seguinte forma: 1, "O ambiente virtual no apoio às atividades de ensino presenciais”, traz uma reflexão sobre a formação acadêmica apoiada nas TICs. A seção 2, intitulada “A ferramenta wiki - definição conceitual”, discute o conceito da ferramenta e sua contribuição para as atividades de ensino-aprendizagem. A subseção 2.1 relata o público-alvo da atividade e os objetivos nela propostos. Por último, são apresentados, na seção 3, os resultados da aplicação da atividade e a avaliação de sua recepção pelos alunos e professores, bem como, seção 4, as considerações finais acerca de todo esse processo de criação, aplicação e avaliação da atividade através da ferramenta wiki.

\section{AMBIENTE VIRTUAL NO APOIO ÀS ATIVIDADES DE ENSINO PRESENCIAIS}

A utilização de AVEAs, como o Moodle, está crescendo no âmbito das instituições de ensino e, assim, modificando a formação universitária atual. A incorporação crescente das TICs ao processo de ensino-aprendizagem traz novas possibilidades ao romper barreiras culturais, linguísticas, geográficas e temporais. Ainda, vem dinamizando os modos de ensinar e aprender, como pontua Neder (2009):

A estrutura EAD modifica o esquema de referência, associado à presença do professor e do estudante, uma vez que decompõe o ato pedagógico em duplo momento e lugar: o ensino é mediatizado; a aprendizagem resulta do trabalho que o aluno realiza; a reação deste ensino chega indiretamente ao professor, através dos tutores; a interação, que em sala de aula constitui o mecanismo de ajustamento do processo de ensino-aprendizagem, é em grande parte reduzida (NEDER, 2009, p.99).

Neste sentido, em consonância com o pensamento de Imbernón, "se a educação dos seres humanos pouco a pouco se tornou mais complexa, o mesmo deverá acontecer à profissão docente” (2006, p. 8), o que remete ao contexto do ensino mediado por tecnologias nas modalidades presencial e a distância, em seus diversos níveis de ensino.

Os AVEAs, alicerçados sob o princípio da aprendizagem colaborativa, configuram-se em ambientes nos quais a comunicação tem sua centralidade na leitura e interpretação de materiais alocados em diversos suportes: fóruns, chats, wikis, blogs, etc. Nesses ambientes interagem vários participantes e, assim, tornam-se imprescindíveis as formas de mediação.

Segundo Bohadana e Rosado (2007), algumas características que os AVEAs, em geral, favorecem são: (a) a troca de idéias entre os indivíduos, mesmo que estas sejam diferentes; (b) o diálogo questionador; (c) a reflexão do pensamento individual; (d) a negociação como meio de se atingir objetivos em comum; (e) o desenvolvimento da capacidade de inferir; (f) a troca de 
experiências sobre as questões trabalhadas e de como se pode agir sobre elas; (g) a interação entre sujeitos em tempo e espaços distintos; e (h) execução de trabalhos coletivos.

Belloni (2008) enfatiza o conceito de mediatização - diferente da mediação física entre professor e aluno. Na modalidade EAD a diferença está nas dimensões espácio-temporais possibilitadas pela confluência de diversas mídias nas experiências de ensino-aprendizagem:

\begin{abstract}
“mediatizar” será uma das competências mais importantes e indispensáveis à concepção e realização de qualquer ação de EAD. De certa forma, ao preparar suas aulas e os materiais que vai utilizar, o professor "mediatiza", embora o meio mais importante neste caso seja a linguagem verbal direta, o que significa que mediatizar o ensino não é uma competência totalmente nova. O que é novo é o grande elenco de mídias cada vez mais “performantes” disponíveis hoje no mercado e já sendo utilizadas por muitos dos aprendentes fora da escola (BELLONI, 2008, p. 62).
\end{abstract}

Para melhor compreender o papel que as TICs podem desempenhar na formação profissional, um ponto de partida interessante é reconhecer que os participantes de um AVEA vivenciam experiências que lhes conferem certo "poder" de descobertas, alterações e simulações de sua própria realidade; interação com diferentes opiniões, textos e imagens de todos os tipos, que circulam pelas suas mãos e olhos.

Segundo Lévy (1998), qualquer reflexão séria sobre o devir dos sistemas de educação e formação na cibercultura deve apoiar-se numa análise prévia da mutação contemporânea da relação com o saber. $\mathrm{O}$ autor acredita que, nessa análise, deve-se levar em consideração a velocidade do surgimento e a renovação dos saberes, alertando para o fato de que o que a pessoa aprende no início de sua profissão pode tornar-se obsoleto ao final de sua carreira.

Especialmente na área das licenciaturas, há uma preocupação recorrente de que futuros professores familiarizem-se e apropriem-se das TICs para incorporarem em suas propostas didáticas, uma vez que, em maior ou menor proporção, essas tecnologias atingem diretamente a vida de todos os seres humanos. Portanto, a formação universitária articula-se não somente para o (re)conhecimento de novas tecnologias, mas, sobretudo, para a utilização ativa das mesmas.

Como uma tendência nas práticas educacionais contemporâneas, têm-se observado cada vez mais a adoção do modelo híbrido ou blended learning - ou seja, a combinação de atividades parcialmente a distância e presenciais. Atividades desse caráter trazem vantagens temporais e até mesmo financeiras, inclusive esse é um dos motivos que contribuiu para a consolidação da modalidade EAD em nosso país, pois “além da vantagem óbvia de não incorrer em despesas de viagem, a aprendizagem online oferece muitas outras vantagens para o aluno, próprias ao estudo via redes eletrônicas” (LITTO, 2010, p. 53).

Pesquisas também apontam o uso de AVEA no ensino presencial em cursos de PósGraduação lato e stricto sensu como uma perspectiva que representa uma abordagem sintonizada com a cultura da sociedade da informação, na busca por uma sociedade do conhecimento (CASTRO; CARBONI, 2009). Assim, o cenário atual é semelhante ao que já ocorreu em épocas anteriores quando das primeiras inserções de vídeo e áudio em sala de aula, ou seja, tecnologias que já estavam cotidianamente agregadas à cultura.

Delgado e Haguenauer (2010) também apresentam um estudo sobre a percepção de professor e alunos a respeito do uso de AVEA como suporte às práticas pedagógicas tradicionais. Foi evidenciado que para o professor, o AVEA representou a possibilidade de dinamizar sua metodologia de trabalho através ferramentas disponibilizadas para inserção de materiais e 
atividades e também pela facilidade de não precisar corrigir atividades manualmente. Já os alunos desta pesquisa, demonstraram boa aceitação ao AVEA e destacaram as ferramentas a importância das ferramentas de interação no seu processo de ensino-aprendizagem, pois representaram, no momento, uma novidade na comunicação entre seus pares.

Embora já existam pesquisas sobre a temática aqui apresentada, ainda são recentes os estudos que se propõem a analisar as modificações didáticas e pedagógicas que a implementação de um AVEA pode significar na formação universitária presencial. Com certeza, esses estudos revelam uma realidade recente e em processo de constituição de uma identidade profissional pautada pelo uso de TICs. Buscando compreender esse processo, o presente artigo traz a análise de uma atividade com a ferramenta Wiki, enquanto recurso de um AVEA, a fim de traçar os caminhos percorridos por essa nova forma de aprender e ensinar e compreender como seus resultados podem auxiliar na elaboração de outras propostas de ensino-aprendizagem.

\section{A FERRAMENTA WIKI - DEFINIÇÃO CONCEITUAL}

Atualmente, a expressão “ensino mediado por tecnologias” tem sido utilizada com bastante frequência na elaboração de propostas didáticas de diversas modalidades de ensino. Isso porque se evidencia um novo paradigma educacional pautado pela vivência do sujeito contemporâneo, que cada vez mais se vê rodeado de aparatos tecnológicos, possibilitando novas formas de acesso à informação e ao conhecimento que são capazes, inclusive, de desempenhar funções cognitivas humanas.

Face à velocidade de informações propiciadas pela navegação em rede, novas possibilidades de acesso à educação por públicos remotos e distintos foram emergindo, como assinala José Manuel Moran (2002):

\footnotetext{
Na medida em que avançam as tecnologias de comunicação virtual (que conectam pessoas que estão distantes fisicamente como a Internet, telecomunicações, videoconferência, redes de alta velocidade) o conceito de presencialidade também se altera. Poderemos ter professores externos compartilhando determinadas aulas, um professor de fora "entrando" com sua imagem e voz, na aula de outro professor. Haverá, assim, um intercâmbio maior de saberes, possibilitando que cada professor colabore, com seus conhecimentos específicos, no processo de construção do conhecimento, muitas vezes a distância (MORAN, 2002).
}

Para o autor, o ensino deve ocorrer de forma interacional, ou seja, deve-se saber mediar expectativas individuais às do grupo, conciliar informação e compreensão e justificar a presença física ou virtual com construções de conhecimento significativo. E essa interação está diretamente associada ao número de participantes envolvidos no processo de ensino-aprendizagem, bem como independe da presença física ou virtual: "teremos aulas à distância com possibilidade de interação online e aulas presenciais com interação à distância” (MORAN, 2000, p. 70).

Um recurso hoje disponível e difundido na rede e que também está incorporado em AVEAs é a ferramenta wiki - capaz de mediar produções textuais coletivas e de contribuir para a formação e manutenção de comunidades virtuais, como o caso da tão conhecida enciclopédia Wikipédia. Através dessa ferramenta, um internauta pode alterar qualquer conteúdo apresentado em um site com tal recurso, através do próprio browser utilizado para navegação. Ou seja, logo após editar um texto disponível e clicar no botão de salvamento, a página é atualizada automaticamente 
no site, sem que o autor da versão anterior (ou qualquer outra pessoa) precise aprovar a modificação. Nesse sentido, ninguém possui a posse definitiva sobre texto nenhum. Ou melhor, os textos são de todos, são da comunidade.

Conforme Alex Primo (2003):

\begin{abstract}
o sistema wiki veio permitir não apenas a reunião de dados, mas a própria geração de novos conhecimentos de forma compartilhada entre diferentes sujeitos, a qualquer tempo e de qualquer lugar. Ou seja, não se trata apenas de uma ferramenta de indexação e formatação, mas a criação de um espaço de debate e sintetização de textos. Ou seja, o papel do interagente não é apenas de um bibliotecário, mas verdadeiramente de um autor, no sentido mais estrito da palavra (PRIMO, 2003, p.60).
\end{abstract}

Dessa forma, torna-se muito interessante o uso desta ferramenta na educação, pois, além de trabalhar com questões de escrita e de leitura, é possível a discussão também sobre questões de autoria - o que se torna pertinente em tempos de mudança de paradigma e de alteração de conceitos.

A navegação de forma móvel e flexível se contrapõe com a linearidade que muito conhecemos através da cultura do papel - o manuseio solitário e em "preto e branco" dos livros agora dá lugar às telas coloridas, cheias de recursos multimidias -, permitindo também a leitura em cascata, como no caso dos hipertextos. "O wiki representa, portanto, uma revolução na relação com o texto em termos de propiciar uma série de possibilidades de uso, inclusive como ferramenta auxiliar no ensino” (GOMES, 2007, p. 99).

Configurada em um módulo didático de um AVEA, como o Moodle, a ferramenta wiki pode ser organizada para o trabalho com todos os participantes de uma mesma disciplina ou curso, e também em grupos separados, podendo ser bastante proveitoso para a elaboração de projetos, de artigos e outras produções que exijam um enfoque mais direcionado sobre determinado tema. Para Abbeg (2009):

\footnotetext{
A principal diferença da ferramenta wiki em relação às outras do Moodle, como por exemplo o fórum, é que as contribuições podem ser permanentemente revisadas e alteradas pelos estudantes e professor, conforme forem sendo construídas. Isso permite o acompanhamento do progresso produtivo, em todos os instantes, o que é uma característica que fortalece a essência da colaboração mobilizando a participação ativa no processo colaborativo (ABEGG, 2009, p. 91).
}

Da mesma forma, é possível a inserção de links e imagens, alteração de fontes em tamanho e cores, permitindo uma estrutura hipertextual e personalizada. Com o uso dessa ferramenta potencializa-se a interatividade, a colaboração e a comunicação, "estratégias que farão parte importante do dia a dia de todos os profissionais no futuro e cujo uso com habilidade será determinante para seu sucesso" (LITTO, 2010, p. 32).

\title{
2.1 Contexto da atividade
}

No Curso de Pedagogia - Licenciatura Plena - Noturno, na grade curricular do $3^{\circ}$ semestre, há uma disciplina intitulada "Tecnologias da Informação e Comunicação Aplicadas a Educação”. Esta disciplina tem por objetivo promover e integrar as TICs no processo educativo através da análise e utilização de diferentes recursos tecnológicos.

O curso é presencial e, como suporte para a realização de atividades didáticas, em 
algumas disciplinas, tem utilizado o AVEA Moodle. Isto está em consonância com a Portaria $\mathrm{n}^{\circ}$ 4.059, de 13 de dezembro de 2004, que em seu artigo $1^{\circ}$ menciona:

As instituições de ensino superior poderão introduzir, na organização pedagógica e curricular de seus cursos superiores reconhecidos, a oferta de disciplinas integrantes do currículo que utilizem modalidade semi-presencial, com base no art. 81 da Lei n. 9.394, de 1996, e no disposto nesta Portaria (BRASIL, 2004).

Segue no parágrafo $\S 1^{\circ}$ do mesmo artigo que a modalidade semi-presencial caracterizase pela realização de:

quaisquer atividades didáticas, módulos ou unidades de ensino-aprendizagem centrados na auto-aprendizagem e com a mediação de recursos didáticos organizados em diferentes suportes de informação que utilizem tecnologias de comunicação remota (BRASIL, 2004).

E, no parágrafo $\S 2^{\circ}$, a regulamentação de que poderão ser ofertadas as disciplinas integral ou parcialmente a distância "desde que esta oferta não ultrapasse 20 \% (vinte por cento) da carga horária total do curso” e também esteja prevista no Projeto Político Pedagógico do Curso.

No segundo semestre de 2010, na disciplina supracitada, foi proposta uma atividade para trabalhar a importância das TICs no processo de mediação pedagógica, por meio da ferramenta wiki. Essa atividade teve como objetivos:

- Possibilitar a discussão sobre a formação de professores frente às tecnologias educacionais.

- Analisar o uso das TICs na educação (vantagens e limitações) como recurso didáticopedagógico para apoio ao processo de ensino-aprendizagem.

$\mathrm{Na}$ orientação inicial da tarefa foi constatado que a grande maioria dos alunos desconhecia as funcionalidades da ferramenta wiki e também não havia tido nenhum contato com AVEAs, o que foi uma justificativa pertinente para a exploração de recursos tecnológicos e a realização de atividades que envolvessem a aprendizagem colaborativa.

Foram propostas questões a respeito do uso de recursos tecnológicos no ensino, bem como fornecidos materiais acerca do tema a fim de que os alunos pudessem construir um texto colaborativo, visto que:

a orientação é que a atividade wiki não seja proposta sem referência bibliográfica desde o início, mas forneça uma boa quantidade de conteúdos culturais que possam ser problematizados, editados ou complementados e, principalmente que esteja acoplado a um recurso hipermidiático no mesmo módulo didático do Moodle (ABEGG, 2009, p. 88).

As colaborações dos alunos foram avaliadas sob os aspectos de coerência e coesão às questões propostas na atividade, bem como a correlação às colaborações expostas pelos demais colegas. Já a avaliação da atividade pela professora formadora e pela professora tutora se deu no alcance, em maior ou menor grau, dos objetivos de aprendizagem já mencionados. 


\section{RESULTADOS}

Conforme definido conceitualmente, a ferramenta wiki é um recurso que permite uma abordagem colaborativa e focada no processo de interação, possibilitando aos participantes de um AVEA integrar novas idéias a um texto já existente, a fim de contribuir com experiências prévias e, assim, construir significado para a nova experiência.

Foi disponibilizado um texto-base, em formato pdf., que tratava do tema central enfocado na unidade de estudo referente a semana em que estava sendo aplicada a atividade, ou seja, a internet como ferramenta de informação, conhecimento e construção do conhecimento. Os alunos também contaram com o apoio de um artigo sobre aprendizagem colaborativa em rede com foco na ferramenta wiki, bem como com a indicação dos seguintes sites:

- Portal do Professor - http://portaldoprofessor.mec.gov.br/index.html: a fim de que o aluno conhecesse e explorasse recursos educacionais disponíveis na atualidade voltado para professores da educação básica;

- Wiki da Escola BR - http://www.escolabr.com/virtual/wiki/index.php?title=P \%C3\%A1gina_principal: para que o aluno realizasse uma pesquisa sobre projetos escolares baseados em wikis que estão sendo desenvolvidos por professores e estudantes de todas as partes do Brasil.

Orientados para a pesquisa nessas referências, os alunos deveriam focar sua construção textual a partir de três questões norteadoras, pois:

a aceitação de uma atividade educacional wiki no Moodle depende fortemente do

planejamento elaborado previamente e do compartilhamento com todos os envolvidos, assim como a explicação do grau em que uma pessoa pode realmente beneficiar-se dessa mediação (ABEGG, 2009, p. 88).

A Figura 1 mostra a interface inicial da atividade no AVEA Moodle da disciplina:

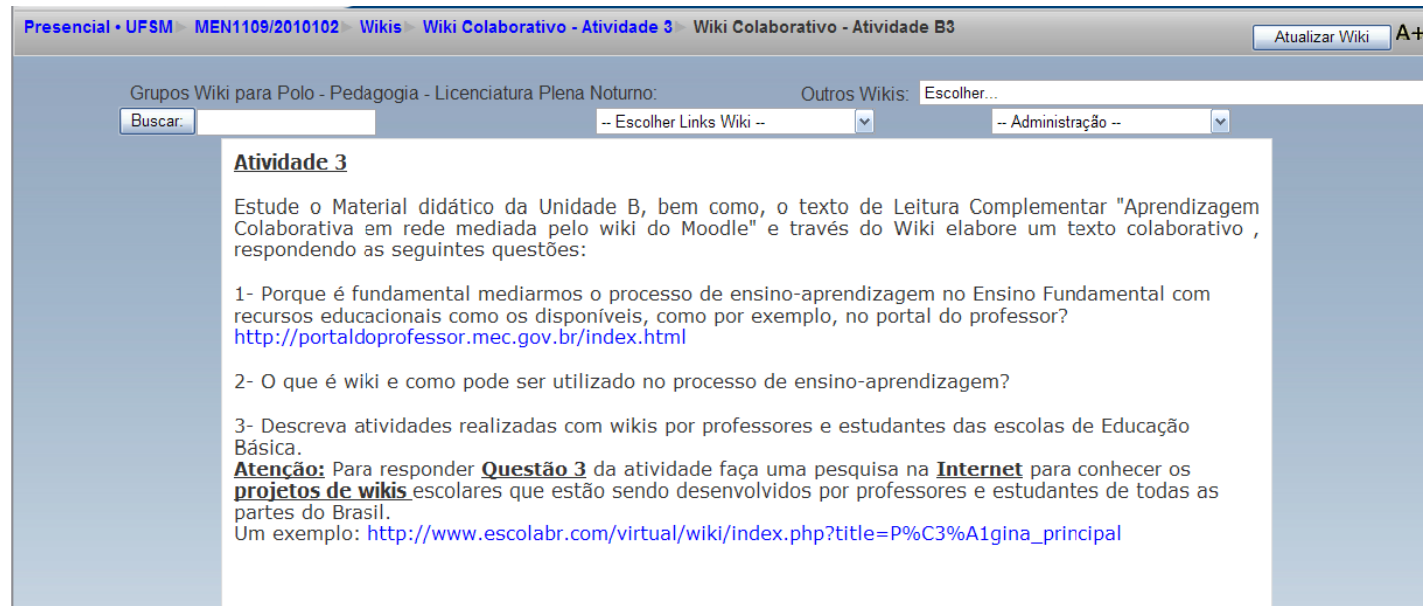

Figura 1: Proposta de atividade com a ferramenta wiki do Moodle.

A partir do tema proposto para a discussão: uso das TICs no ensino e sua delimitação 
em três questões, a atividade desenvolveu-se no período de duas semanas. Não houve a separação em grupos de alunos - foi disponibilizada uma única wiki que poderia ser acessada, escrita e editada por todos os alunos da disciplina que, ao todo, eram 32. Justifica-se a escolha de tal procedimento devido à dinâmica da disciplina alternar momentos presenciais e a distância, o que permitiu um contato mais direto com os alunos sobre dúvidas e êxitos que estavam tendo no desenvolvimento da atividade e também a conversação prévia entre os alunos e professores sobre a melhor forma de colaborar na wiki.

Como a relação tempo/espaço em atividades a distância é diferenciada da relação educativa tradicional, salienta-se a importância da relação dialógica entre orientador pedagógico (professor e/ou tutor) e aluno:

Na educação a distância a interlocução entre tais agentes é exclusiva, e, paradoxalmente ao sentido atribuído ao termo 'distância', ambos devem estar permanentemente em contato mediante a instituição de um processo dialógico, do qual o entorno, o percurso, as expectativas, as realizações, as dúvidas, as dificuldades, etc. sejam elementos dinamizadores (NEDER, 2009, p. 143).

Em relação ao número de participantes envolvidos no processo de ensinoaprendizagem, destaca-se o pensamento de Moran (2000), já mencionado na definição conceitual. Este fator é proporcional ao grau de interação, ou seja, quanto mais participantes, mais interação. O mesmo autor reforça que a combinação de momentos presenciais e a distância estimulam a construção de conhecimento que, atualmente, não pode ser pensada somente a partir de locais determinados ou conhecidos:

A mobilidade e a virtualização nos libertam de espaços e tempos rígidos, previsíveis, determinados. Na educação, o presencial se virtualiza e a distância se presencializa. Os encontros em um mesmo espaço físico se combinam com os encontros virtuais, pela internet (MORAN, 2007, p. 89).

As colaborações iniciais já demonstram que os alunos preocuparam-se em responder às questões propostas para análise da ferramenta wiki, conforme se pode observar na Figura 2:

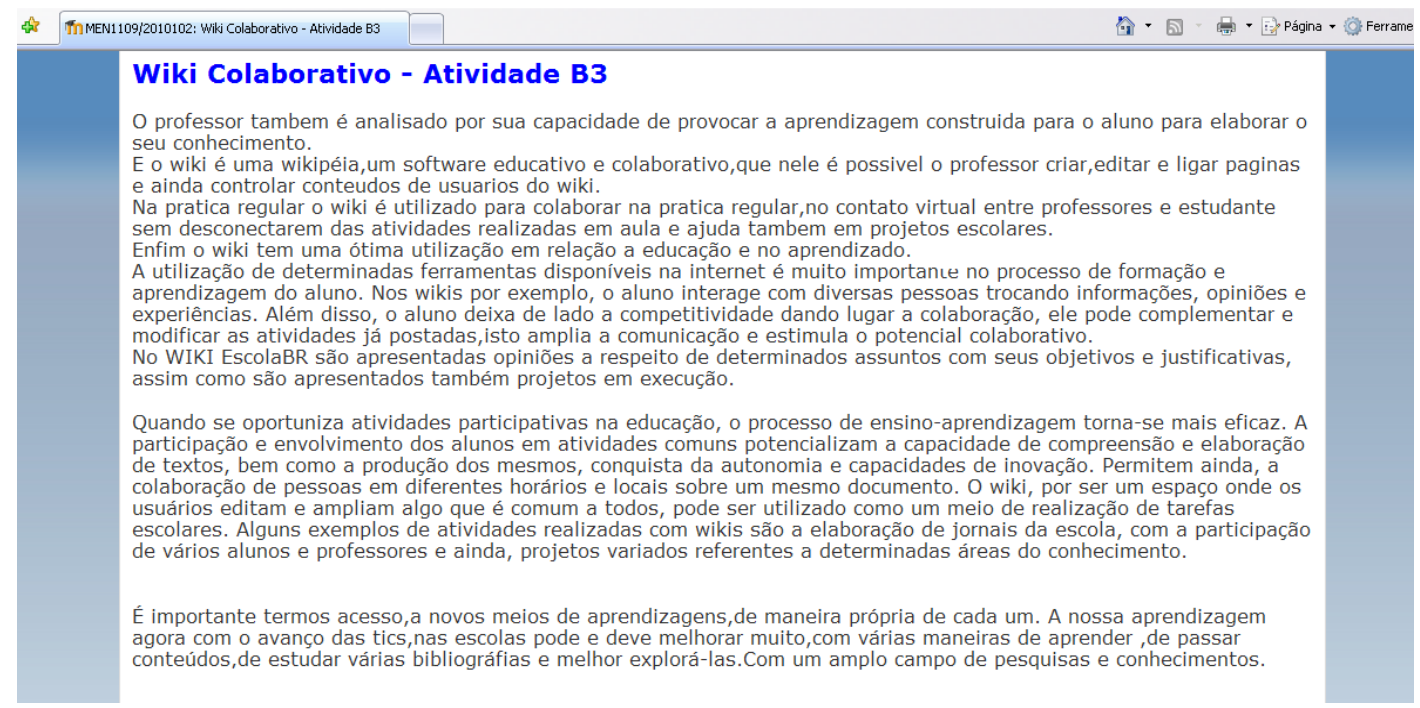

Figura 2: Primeiras produções na wiki. 
Analisando essas intervenções pode-se considerar que realizar uma atividade vivenciado-a propriamente - no caso, falar sobre ferramenta wiki a partir do uso da mesma -, tornase mais próximo do participante que está interagindo com o recurso e permite uma discussão mais aprofundada, auxiliando assim, na compreensão de estratégias e posturas que o professor deve adotar frente ao uso das tecnologias.

O profissional que concentra seus esforços na criação de ambientes e tarefas que permitam aos alunos descobrir, por si mesmos (fatos e conhecimentos sob diferentes possibilidades de interpretação da informação obtida), nunca será substituído na aprendizagem presencial ou a distância (LITTO, 2010, p. 16).

Durante o período de realização da atividade, muitos alunos interagiram constantemente com a professora formadora e com a professora tutora, mencionando os materiais que estavam pesquisando e se poderiam ampliar a discussão para o uso de tecnologias na educação de forma mais geral. Nesse ponto, considera-se que o primeiro objetivo foi cumprido com sucesso: possibilitar a discussão sobre a formação de professores frente às tecnologias educacionais, pois ficou evidente a reflexão do tema proposto e a percepção de que, para trabalhar com tecnologias, o professor em formação na contemporaneidade necessita conhecer todo um referencial teórico e prático capaz de subsidiar a elaboração de propostas didáticas qualificadas:

O processo de formação deve dotar os professores de conhecimentos, habilidades e atitudes para desenvolver profissionais reflexivos ou investigadores. Nesta linha, o eixo fundamental do currículo de formação do professor é o desenvolvimento da capacidade de refletir sobre a própria prática docente, com o objetivo de aprender a interpretar, compreender e refletir sobre a realidade social e a docência (IMBERNÓN, 2006, p. 39)

Embora a utilização das TICs seja realidade recente no contexto da formação de professores, especialmente no ensino presencial, o desenvolvimento profissional docente, na perspectiva de Imbernón (2006), pressupõe o exercício de habilidades técnicas e cognitivas que busquem ultrapassar a fronteira entre os campos pessoal e profissional. $\mathrm{O}$ autor destaca cinco importantes linhas de atuação que devem permear esse processo: (1) reflexão entre prática-teoria; (2) troca de experiência entre os pares; (3) união; (4) incentivo crítico, e; (5) desenvolvimento profissional do centro educativo.

A interação em AVEAs, a utilização de ferramentas em tempo real (síncronas) ou não (assíncronas), as formas diferenciadas de mediação entre professores e alunos e a aprendizagem centrada mais no processo do que na transmissão, têm contribuído para novas possibilidades de conceber a profissão docente e, até mesmo, para a reforma na estrutura curricular de cursos de formação de professores.

O primeiro objetivo tornou-se ainda mais evidente ao longo das contribuições quando, no wiki colaborativo, os alunos dividiram o texto em seções (figura 3): 
Análise dos meios tecnológicos

Na situação atual em que vivemos tem se um alto nível de tecnificação, para podermos dominar alguns desses meios tecnológicos se faz necessário o domínio da escrita em suas várias dimensões, usando palavras números e imagens. Hoje em dia sempre que for preciso comprovar algo, enfrentar a concorrência ou simplesmente conversar através da internet, faz-se com o auxilio da escrita deixando em segundo lugar a fala propriamente dita, até para preservar a imagem. Devido a essa importância os alunos deverão aprender a expressar-se com precisão, objetividade e clareza por escrito. Nesse sentido o professor é um orientador e um motivador para a aprendizagem, desde que saiba como e com o auxilio de que fará isso.

Os professores precisam desenvolver no aluno a capacidade de autonomia, de agir como cidadão, interagir com o mundo informatizado e sem se deixar o aluno ser manipulado. De posse dessas aprendizagens, esse aluno se tornará um cidadão capaz de atuar no convívio democrático.

O wiki é uma plataforma disponível na internet, onde é possível estudar, colaborar e interagir. Por estar relacionado ao conhecimento, o seu uso promove a interação social, amplia a comunicação e como uma conseqüência aumenta a aprendizagem. Nele é possível construir um saber coletivo em busca de um produto final mais completo.

Percebe-se que a grande maioria das atividades realizadas são de conversas via web para solucionar dúvidas e relatar experiências. As atividades são de fáceis postagens mas um dos pontos ruins é a falta de interesse e participação.

No Brasil há quatro projetos concluídos, sete em andamento e um projeto proposto, o Projeto Amadis, todos ligados à wiki no sentido de pesquisar e discutir a forma que os professores e alunos estão utilizando esta ferramenta.

Um wiki é um conjunto de páginas na internet que qualquer pessoa pode editar e aprimorar, é uma espécie de documento colaborativo. Foram criados inicialmente para facilitar a comunicação entre desenvolvedores de software, mas passaram a ser usados por públicos diferentes para diversas finalidades, entre elas a educação.

O wiki pode auxiliar na realização de dinâmicas para descontrair e aprimorar os participantes de um curso à distância, por exemplo. Atividades desse tipo possibilitam que os alunos entrem em contato com os demais e dessa forma

estabeleçam novas relações de amizade, trabalho e companheirismo.

Figura 3: Exemplo de uma seção produzida na wiki.

Para Bohadana e Rosado (2007), nas atividades wikis a regra geral é não existir controle central, pois se espera que as sucessivas contribuições dos internautas sobre o texto constituam com o tempo um consenso, um texto profundo e refinado a respeito do tema proposto.

O segundo objetivo da atividade era de analisar o uso das TICs na educação (vantagens e limitações) como recurso didático-pedagógico para apoio ao processo de ensino-aprendizagem. Em relação a isso, apontam-se como vantagens que o uso de uma ferramenta no AVEA nunca acontece de forma isolada, pois desde o acesso ao ambiente o participante já encontra recursos que instigam a interação, como ferramentas de comunicação, imagens e texto, além de estar conectado à internet, podendo acessar outras ferramentas, em outros espaços. Outra vantagem é que o AVEA torna-se um ponto de referência, propiciando a comunicação independente dos encontros presencias. De forma geral, o uso das TICs na formação de professores representa 0 desenvolvimento de profissionais com visões renovadas.

Como limitações apontam-se que nem todos possuem acesso a recursos tecnológicos, começando pelos próprios alunos da disciplina. Essa é uma realidade que se estende às escolas, que será seu principal campo de atuação. Ainda, houve casos isolados de resistência ao uso TICs; mais especificamente dois, que relataram não estarem familiarizados com o uso de recursos tecnológicos e que também não tinham interesse em apropriarem-se dos mesmos, pois estavam matriculados em curso presencial e não possuíam acesso à internet em domicílio, bem como não dispunham de tempo para realizar atividades nos laboratórios de informática da instituição.

A atividade encerrou com a participação de $90 \%$ dos alunos inscritos na disciplina, cerca de 28, nos quais apresentaram produções individuais de um ou dois parágrafos, constituindo um texto colaborativo de dez páginas com inserção de hiperlinks e imagens e com a mesma cor e tamanho de fonte. Tal resultado pode ser considerado um sucesso pelo fato da disciplina apresentar atividades a distância em um curso presencial, o qual apresenta completamente outra estrutura pedagógica, didática e interpessoal em relação a um curso totalmente a distância e, assim, pode apresentar baixo índice de realização de atividades colaborativas, como a wiki: 
É de se esperar, tendo em vista a cultura hegemônica de nossa sociedade, que a atividade wiki do Moodle não seja bem aceita e realizada pelos estudantes. Isso, porque trata-se de uma ferramenta de produção colaborativa, num escopo competitivo como o ambiente escolar e ainda não estar integrada no cotidiano desta modalidade de trabalho (ABEGG, 2009, p. 87).

Cabe ressaltar que a atividade foi avaliativa e isso também contribuiu para a participação dos alunos. O principal critério de avaliação foi a coerência textual às questões norteadoras da tarefa, bem como a coerência às colaborações dos demais colegas, ou seja, se não apresentava tangenciamento da temática apresentada na orientação da tarefa. O número de intervenções de cada participante não foi aspecto relevante para a avaliação, pois como primeira experiência com escrita colaborativa, foi considerada apenas a qualidade da postagem e não a quantidade.

Como a ferramenta wiki do Moodle não possui um gerenciador próprio ou moderador das postagens realizadas esse papel acabou sendo realizado pela professora-tutora da disciplina por escolha dos alunos, pois na medida em que realizavam as inserções, questionavam a mesma sobre a qualidade e coerência. Foi percebido que isto ocorreu pelo fato de nenhum aluno ter se sentido a vontade para intervir nas colaborações dos colegas, embora tenha sido sinalizado previamente que poderia ser feita a correção e edição quando houvesse necessidade.

A experiência vivenciada com a ferramenta wiki do Moodle, em curso presencial, mostrou que a interação e a colaboração são as categorias da experiência humana que mais se destacaram, uma vez que “a formatação de um curso via internet é diferente do esquema presencial porque, na web, a aprendizagem depende mais da interação dos participantes” (LITTO, 2010, p. 61) e a colaboração, sinônimo de cooperação, é estimulada pela interação entre os participantes do AVEA ao realizarem ações não-individualizadas como a escrita coletiva.

No último encontro presencial, por ocasião do término da disciplina, os relatos sobre a atividade realizada foram, em geral, positivos. Sendo as principais impressões sobre a utilização da ferramenta wiki: possibilidade de escrita coletiva com recurso online; construção textual mais dinâmica com visualização mais rápida da estrutura; inserção de links e imagens; alterações e revisões a qualquer momento.

Outros apontamentos também surgiram como a eficiência da ferramenta para atividades em grupo, pois nesse caso fica mais fácil para os alunos já irem construindo a tarefa diretamente na ferramenta e que esta também pode ser utilizada como mural de informações da turma.

Dessa forma, acredita-se também que, em alguma proporção, os professores em formação capacitaram-se para o uso das TICs na educação através da realização de atividades de pesquisa na internet, da utilização de recursos do AVEA Moodle e da colaboração na ferramenta wiki.

\section{CONSIDERAÇÕES FINAIS}

Um ambiente virtual instiga a curiosidade em torno de suas funcionalidades e também enfatiza os aspectos ativos e participativos do processo de ensino-aprendizagem. Permite desenvolver a aprendizagem a partir da navegação pela internet - quando utilizado na formação acadêmica a distância ou presencial. Porém, essa formação supõe também uma "constante indagação colaborativa para o desenvolvimento da organização, das pessoas e da comunidade que 
as envolve” (IMBERNÓN, 2006, p. 81).

Nesse sentido, a utilização da ferramenta wiki representou, no contexto da formação acadêmica presencial, uma forma diferenciada de construir um texto que instigou a interação e a colaboração entre os alunos e professores na medida em que um texto escrito coletivamente vai passando pela visão crítica de vários sujeitos.

Com esta experiência, foi possível visualizar que prática e teoria devem estar conectadas e ocorrerem de forma concomitante, pois não é mais possível que o professor, seja em formação ou já em exercício, fique estagnado no modelo de educação massificador focado na transmissão de conteúdos. É preciso que se experimente e que se vivencie as possibilidades que as TICs podem oferecer ao campo da educação, numa sociedade já informatizada há um bom tempo.

O uso de AVEA e as ferramentas nele agregadas foram, em geral, bem aceitos e com isso foi possível elencar mais vantagens do que desvantagens. As poucas desvantagens apresentadas estão relacionadas ao não acesso a recursos tecnológicos, ou seja, ao não conhecimento e/ou à resistência ao uso de tecnologias, o que implica uma visão pedagógica tradicional, não compatível com a cultura contemporânea.

Fica evidente que devido a utilização de AVEAs no ensino presencial ser uma realidade recente, ainda são poucas as análises sobre seu impacto na formação profissional que caminha para constituir uma nova identidade metodológica, tal como é outra a relação com o saber e o conhecimento que se estabelece em cursos a distância. No entanto, esta tendência de modelo híbrido tem sido recorrente pois os recursos tecnológicos convergem cada vez mais para serem grandes aliados de professores e alunos.

\section{REFERÊNCIAS BIBLIOGRÁFICAS}

ABEGG, Ilse. Produção colaborativa e diálogo-problematizador mediados pelas Tecnologias da Informação e da Comunicação Livres. 2009. 184 f. Tese (Doutorado em Informática na Educação) - Universidade Federal do Rio Grande do Sul, Porto Alegre, 2009.

ABDO, Alexandre Hannud. Wiki. In.: SPYER, Juliano (Org.). Para entender a internet: Noções, práticas e desafios da comunicação em rede. 2009, p. 57-58. Disponível em: $<$ http://paraentenderainternet.blogspot.com>. Acesso em: 18 fev. 2011.

BELLONI, Maria Luiza. Educação a distância. 5. ed. Campinas, SP: Autores Associados, 2008.

BRASIL. Portaria n. 4.059, de 13 de dezembro de 2004. Regulamenta a modalidade semipresencial. Diário Oficial [da] República Federativa do Brasil, Brasília, DF, 13 dez. 2004. Disponível em: <http://portal.mec.gov.br/sesu/arquivos/pdf/nova/acs portaria4059.pdf $>$. Acesso em: 25 mai. 2011.

BOHADANA, Estrella.; ROSADO, Luiz Alexandre da Silva. Autoria coletiva na educação: análise da ferramenta wiki para cooperação e colaboração no ambiente virtual de aprendizagem Moodle. In: Encontro de Educação e Tecnologias de Informação e Comunicação, 5.; 2007, Rio de Janeiro. Anais eletrônicos... Rio de Janeiro: Universidade Estácio de Sá, 2007. Disponível em: $<$ http://alexandrerosado.net78.net/attachments/004 ETICVAlexandreRosado.pdf $>$. Acesso em: 23 mai. 2011.

CASTRO, Rafael Fonseca de; CARBONI, Simone. Ambientes Virtuais de Aprendizagem (AVAS) como instrumentos de suporte ao ensino presencial tradicional: um estudo de caso em curso de PósGraduação. In.: Congresso de Iniciação Científica, 18.; 2009, Pelotas. Anais eletrônicos... Pelotas: Universidade Federal de Pelotas, 2009. Disponível em: < 
http://www.ufpel.edu.br/cic/2009/cd/pdf/CH/CH 00990.pdf>. Acesso em: 20 out. 2011.

DELGADO, Laura Maria Miranda; HAGUENAUER, Cristina Jasbinschek. Uso da Plataforma

Moodle no Apoio ao Ensino Presencial: Um Estudo de Caso. Revista EducaOnline, Rio de Janeiro, UFRJ, v. 4, n. 1, jan/abril de 2010.

DIAS, Simone Regina. Reflexão sobre a Lingu@guem na Educação a Distância. In.: MELO, Maria Taís de; CARVALHO NETO, Cassiano Zeferino de; SPANHOL, Fernando José (Orgs.). Hipermídias: interfaces digitais em EAD. São Paulo: Laborciência, 2009. p. 25-39.

GOMES, Mayra Rodrigues. A ferramenta wiki: uma experiência pedagógica. Revista Eca XII, São Paulo, USP, 8 jul. 2007.

IMBERNÓN, Francisco. Formação docente e profissional: formar-se para a mudança e a incerteza (Coleção questões da nossa época) - 6 ed. São Paulo: Cortez: 2006.

LÉVY, Pierre. Educação e cybercultura. São Paulo: Editora 34, 1998.

LITTO, Frederic. Aprendizagem a distância. São Paulo: Imprensa Oficial do Estado de São Paulo, 2010.

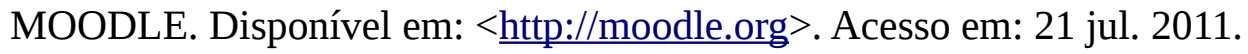

MORAN, José Manuel. Mudar a forma de ensinar e de aprender com tecnologias. Revista Interações, São Paulo, v. 5, n.9, p. 57- 72, 2000.

O que é educação a distância. 2002. Disponível em:

$<$ http://www.eca.usp.br/prof/moran/dist.htm>. Acesso em: 02 nov. 2010.

. A Educação que desejamos: novos desafios e como chegar lá. 4 ed. Campinas, SP:

Papirus, 2007.

NEDER, Maria Lúcia Cavalli. A formação do professor a distância: desafios e inovações na direção de uma prática transformadora. Cuiabá: EdUFMT, 2009.

PRIMO, Alex. Hipertexto cooperativo: uma análise da escrita coletiva a partir dos blogs e Wikipédia. Revista FAMECOS, Porto Alegre, n. 22, pp. 71-89, 2003.

PORTAL DO PROFESSOR. Disponível em: <http://portaldoprofessor.mec.gov.br/index.html>. Acesso em: 22 set. 2010.

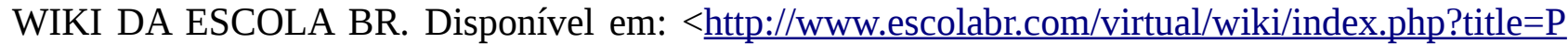
\%C3\%A1gina principal>. Acesso em: 22 set. 2010. 
i Modular Object-Oriented Dynamic Learning Environment - um ambiente de aprendizagem de código livre, aberto e gratuito que possui funcionalidades e recursos como o blog, wiki, glossário, chat, tarefa, questionário, entre outros (MOODLE, 2011). 